\title{
SME Cloud Adoption in Botswana: Its Challenges and Successes
}

\author{
Malebogo Khanda \\ Lecturer, Faculty of Computing, \\ Botho University, \\ Gaborone, Botswana
}

\author{
Srinath Doss \\ HOD, Faculty of Computing \\ Botho University \\ Gaborone, Botswana
}

\begin{abstract}
The standard office or business in Botswana hosts their resources in-house. This means that a company will have their hardware, software and support staff as part of their daily work operations. Technology has brought a shift to the office environment with Cloud Computing. Botswana has seen the growth of the Cloud Technologies, within its own boundaries where companies have embraced the new technology to mobilize and push their operational agenda with the same tenacity as the rest of the world using the technology. Cloud computing has taken root in Botswana and it shows that a lot of SMEs are using cloud computing, whilst some are non-adopters to the technology. Edgar Tsimane reported the take up on cloud computing in Botswana. Botswana uses the National ICT policy to guide on technological advances and development, i.e the Maitlamo policy. This paper is considering aspects influencing the company's decisions on utilizing the cloud as a service, both opportunistic and challenges. Some of the questions to address for the study are: how effective is cloud computing for businesses in Botswana; what challenges and successes these companies have had, is there any particular framework they had to follow to guide them in adopting the services? Finally, the paper was to take consideration in recommending a framework that can be adopted within the Botswana.
\end{abstract}

Keywords-Cloud computing; SME's; cloud computing services; cloud business processes; cloud computing framework; cloud deployment models; cloud computing services model

\section{INTRODUCTION}

Botswana Government and various Information and Communications Technology (ICT-based) companies have investments in improving local Internet connectivity. The Internet acts as the major platform for cloud usage by almost everyone who uses cloud computing, as resources are online. As indicated by Dr Seleka, Botswana is still working on a mandate to utilize the cloud; therefore identifying the challenges and successes of the service, combined with efforts made by the government, will help equip SME's with the necessary tools to guide them to adopt cloud services. The study first explores what the cloud means to the general public; then, it considers the usage of the Cloud by Small to Medium Enterprises (SME's) in their operational activities. The study will also explore the challenges and successes involved in cloud computing contrasting companies that are using the cloud and those that are not using it. This will help build up or identify a framework that can be adopted in Botswana to help SME's in their transition to supporting cloud based services.
Botswana has seen a number of companies adopting Cloud Computing. For example, Botswana Post launched Poso Cloud for its clients in 2013. Some of the companies also using cloud computing are IT-IQ and Dimension Data. Edgar Tsimane reported that BIH "seeks to utilise cloud computing in the near future to provide services to its start-up companies and willing tenants". Dr Geoffrey Seleka, Senior Director BIH, added that "the intention is to see how BIH can also replicate cloud usage in a national settin".

Cloud Computing involves service and product under one umbrella, thus the "Cloud". The usage and implementation of cloud services are also influenced by the legal systems and policies in institutions or guided by international standards from the Institute of Electrical and Electronics Engineers (IEEE). With new technologies, or advancing technologies, concepts are adopted to influence standardization of resources to allow for easy communication and integration. This then denotes, that the Cloud should have some basic concepts that one could analyze before selecting the cloud services.

\section{LITERATURE REVIEW}

Different countries in the world have shown that cloud computing adoption is necessary. For examples, countries like Kenya, Nigeria, South Africa, Ghana, India, England and Australia are amongst a number of countries across the globe that have embraced the use of Cloud Computing Technology.

\section{A. Small-To-Medium Enterprises Growth and Technology Adoption}

SME's are recorded to be more than $90 \%$ of all businesses in the Sub-Saharan Africa, consequentially thus considered to contribute a lot to a country's GDP. Albeit the controversy on which size business contributes more to a country's GDP, the fact that SME's are greater in number than larger enterprises, indicates a vital role SME's play in the economy. The SMEs' growth and sustenance hence becomes detrimental, and Robert indicated that there is need to focus on "technology advisory" for SMEs' [9], [10]. In his own words, his resolve was:

"These firms, then, need new and innovative types of technologies, such as Software-as-a-Service (Saas), virtualization, and cloud computing; these firms also need (and deserve) a better kind of technology advisory delivery model to provide them with research, analysis and insight."

Botswana is a developing country, and is recognized as one of the fast growing economies in the world [18], [20]. 
Botswana has seen growth in businesses in general, and technology seeing a big growth whereas internet access, telecommunications (including mobile), transport, banking and education have also improved. The Maitlamo policy and the implementation of the E-government portal in 2012 are acclaimed to boost the use of technology in the country, Botswana.

\section{B. Botswana E-Readiness}

The Botswana government rolled out the Maitlamo policy since 2004, final report, which represented Botswana's aim to have an internet environment for e-services in government department. These included areas on e-health, e-education (termed as e-Learning), e-legislation and connectivity to homes and communities, the Information and Technology sector, and making sure that infrastructure resources for availing these other services is also available. To continue the many efforts to implementing these pillars for Maitlamo ICT Policy, in 2012 the Ministry of Transport and Communications, Honorable Minister Nonofo Molefi, launched one of the most awaited service, the Botswana National e-Government Strategy, to tag along government services to be availed online [6]. This brought about the creation of Botswana Fiber Networks enterprise (BOFINET), whose mandate is to provide network infrastructure (use of FIBER connections), and connectivity to rural and urban areas (BOFINET). BOFINET runs as a sprectra over $9000 \mathrm{~km}$ across the country, and has seen implementation in rural and urban areas. Areas like Selebi Phikwe, Tsabong, Kachikau, and Mohembo projects on the fiber deployment are ongoing.

Many companies and government entities have taken advantage of the introduction EASSy and WACS. This was a big investment by Botswana to provide a spread on connectivity to the country [5].

\section{Some of the efforts in Botswana on internet access are:}

Botswana Post, a private organization reached out to 81 communities, mostly villages in Botswana through e-centers, called kitsong centers [13], [16]. ICT training, e-services like faxing, emailing, research and telecommunication and postal services are provided in the Kitsong centers.

1) Botswana is hosting the TRASA, to regulate and improve Postal and ICT business environment in the SADC region (IST-Africa). This put, a subtle trust on the infrastructure of Botswana Telecommunication organization, allowing exploitation of available resources and known available services to support the mandate of TRASA.

2) The introduction of internet services, like the BOFINET, the growth of internet service providers across the country to allow home and office access, indicates development in internet access. BOCRA reported having registered 64 facilities, including satellite hospitality facilities, which are being used in urban areas where a form of on ground physical infrastructure is unavailable in BOCRA.

3) Mobile services grew with the country boasting with 3 Private Telecommunication Organization, i.e. Orange Botswana, Mascom Wireless and BeMobile, being the sub- entity of Botswana Telecommunications Corporations. Allowing for mobile growth, inter-relations between international and local PTO's has given benefit to an increased access, as all these network provide affiliate and local mobile internet access.

Many can be said on the Botswana development on technology access. Education, health, agriculture, tourism, the libraries and many other departments, have initiated projects to merge their sectors with the ICT sector.

\section{Cloud Computing and SME Growth}

1) In Botswana: There is neither record nor study of the number of companies that are using cloud services for business operations in Botswana. Companies like Dimension Data, Botswana Post, Acutec and IT-IQ are well known in Botswana as using cloud services, either as a platform, infrastructure, or software service [5]. These being ICT companies, we also learn of universities like Botho University, with the University of Botswana, widely using cloud as a service, for storage, applications, software platforms and development for engines and assisting their clients, student or staff, to have access to more cloud resources.

This identifies "The Cloud" as no foreign tool for businesses in Botswana. The use of Dropbox, Facebook, Flicker, and Google Apps and Drive has emerged with cloud usage, amongst many internet users. Some of these services are widely used by the population, as indicates:

a) It has been recorded in the internet world statistics that Botswana has $31.2 \%$ penetration rate for Facebook subscribers in 2016 Statistics, indicating a highest subscriber in Africa. University of Botswana.

b) The University of Botswana, School of Graduate Studies uses Google Apps for a collaboration of web-based programmes and storage, to allow for communication, collaboration on student learning, repository for students and institution, institutions application availability online with the benefit of any-time access, reduced risk implications, without requiring to purchase software nor hardware, with an easy interface and use by UB.

There are more services on the cloud that are being used by many companies. The sales force and ERP online have also become widely used by projects and client-base companies in Botswana.

2) In Africa: Countries like Nigeria, Kenya, Ghana, and South Africa has done a number of studies on Cloud Computing in Africa. A study in the sub-Saharan Africa identifies Nigeria as an "early adopter" on issues of cloud computing in Africa[2]. South Africa in Southern Africa Development Community (SADC) is known as one of the fastest growing in technology, alongside Mauritius and Zambia, and countries like Madagascar and Mozambique being in the top 10 internet access countries in Africa. Some examples of these countries adoption of Cloud Computing by SME's are: 
a) Nigeria has proven adaptable to cloud computing services. A number of researches show that a number of institutions, and SME's in the country have adopted to the use of cloud services.

b) In one research, about 10 universities were used to investigate the adoption of cloud computing in local institutions [3]. The investigation showed that $90 \%$ of the universities was using cloud computing services. And the services common between the institutions were SaaS, PaaS and IaaS, which each rated at $70 \%, 20 \%$ and $10 \%$ usage (respectively) on average by the universities utilizing the services

c) In another research on SME's adoption issues of cloud computing, showed that though there are issues on the ground to cloud adoption by SME's, that opportunities offered by Cloud Computing are real [2].

d) Kenya has shown great growth in technology development. With the inception of MPESA project and Safaricom enterprise, amongst other technology dynamic stakeholders Kenya is widely and worldly known for its establishments in advancing technology innovations. Considering the SME business at $98 \%$ in Kenya, inevitably it is being considered to provide significant impact on employment (4,6 million people - $30 \%$ of the population), and brings about $18.4 \%$ of the annual country revenue [17]. Safaricom cloud has now taken root in Kenya, and the results of the study indicated that Kenya SME's have adopted to cloud technology in areas as payroll, call conferencing, accounting services, and even online domain hosting for websites. MPESA, a big financial project and widely adopted by many in Kenya, is also part of Safaricom initial projects.

e) South Africa is one of the fastest growing economies in cloud resources. The Deloitte report (2012), shows that SME's are majority players in cloud computing [7]. For example, South Africa hosts about 21 data centers across the country, and IBM launched its first Cloud Data Center in Johannesburg in March 2016. IBM will be using the already available Vodacom data center infrastructure. Development on cloud technology and growth in this case, can piggy back on already existing resources with South Africa, thus it can advance the use of cloud computing.

A telecommunications report indicated that African countries too are adept in developing Cloud services for its clients. MTN, one of the largest telecommunications providers in Africa, is providing a number of cloud services for Nigerian and Ghanian SMEs [3]. MTN is known to provide telephony services to countries even in the south of Africa. It could then only be expected that such services could be adopted by the rest of the world, if they are effectively utilized and scalable as other cloud services.

3) In the World: The Cloud resource is now a world commodity, a necessity from household to business. This is true for most countries, where internet access is readily available, cheaper, and infrastructure is available to house cloud computing services with limited challenges. The developed world, with countries like Australia, England, Japan, New Zealand, and Ireland have shown studies identifying the adoption of Cloud Computing in within their local business, or for regions in such countries.

a) Ireland - a study was conducted where $250 \mathrm{SME}$ companies were surveyed, and the results were concluded that, indeed Irish SME's are well aware of the significance of the adoption of cloud services. Albeit knowing the benefits of cloud computing, Irish SME's were reluctant to adopt this resource, and acknowledged fears concerning "security, poor internet infrastructure, and trust". These fears influenced their lack of adopting the cloud services [7].

b) North east England - is one of the fastest growing technology countries in the world, as one of the developed countries. Hence, it is provided by scalable technologies that deliver services and deliverables any market industry would require. A research conducted in the north east of England showed that cloud computing in the region was matured, even with the complexity and context sensitivity issues [4].

c) Australia - showed very impressive results for 2012 employment by SME's to be at 70\%, with input of AUS $\$ 480$ billion (Australian Dollars), showing a critical role played by SME's for the Australian economy [8]. The survey was conducted to find out the success of cloud computing by SME's in Australia, but limitations on data collection delayed the findings [11].

\section{Cloud Adoption Challenges}

Like many technologies, and its advancement and new developments, Cloud Computing too has a number of challenges like deployment issues, data migration, security, privacy, regulation and cyber-attacks. In developing countries, other issues as water, communication resources, power, and gas can contribute to such challenges. Abubakar et al. added in his study that internet access, online security (trust and privacy) and economic development are common issues for SubSaharan Africa [1].

A research in Nigeria, considered about 10 universities in a survey to measure how they have adopted cloud computing for university operations. The study indicated that there were challenges that the institutions faced. Table I below shows the 
challenges these universities faced [3]. The results depicted very high percentages for challenges the institutions faced in cloud computing adoption.

TABLE I. NigERIA UNIVERSITIES (2014) - CHALlENGES OF ClOUD COMPUTING AdOPTION. SOURCE: AKIN, Et AL. 2014

\begin{tabular}{|l|l|l|}
\hline S/N & $\begin{array}{l}\text { Challenges of using Cloud } \\
\text { Computing }\end{array}$ & \% of Respondents \\
\hline 1 & Data insecurity & 89.3 \\
\hline 2 & Unsolicited Advertising & 64.6 \\
\hline 3 & Lock-in & 77.6 \\
\hline 4 & $\begin{array}{l}\text { Reluctance to eliminate staff } \\
\text { positions }\end{array}$ & 64.6 \\
\hline 5 & Privacy Concerns & 68.9 \\
\hline 6 & Reliability Challenge & 64.2 \\
\hline 7 & $\begin{array}{l}\text { Regulatory compliance } \\
\text { concerns/user control }\end{array}$ & 80.0 \\
\hline 8 & $\begin{array}{l}\text { Institutional culture / Resistance to } \\
\text { change in technology }\end{array}$ & 59.2 \\
\hline
\end{tabular}

1) Cloud Adoption Challenges in Universities: A number of the issues indicated in the Nigerian universities are shared by another study considering cloud adoption in the SubSaharan Africa [2]. These challenges seem very common amongst many countries, and they can be categorized into three: managerial, relational and technical [11].

\section{E. Technology Frameworks}

1) TOE Framework: The TOE framework is widely adopted for cloud computing. This model was developed in 1990 by Rocco DePietro, Edith Wiarda and Mitchell Fleicher. It is based on Technical, Organizational and Environmental (TOE) contexts/aspects of an enterprise that influence organizational operations. It is denoted as a "multi-perspective framework" that can help an organization identify barriers and benefits a technology innovation can bring to an organization, as denoted by the diagram below. A decision on adopting the cloud will be based on the consolidated positive feedback of these aspects.

2) TMR Framework: Companies and customers utilize the TMR frameworks which consider aspects as: Technical, Managerial and Relational, to inform on implementing cloud technologies.

The framework structure first considers the available and current cloud services; then secondly analyzes the organizations needs or requirements looking at the organizations Relations, Managerial and Technical (both internal and external) aspects; then thirdly maps the organizational results to the cloud variables; which finally should influence the adoption decision.

3) ITIL Framework: Information Technology Infrastructure Library (ITIL) is one of the popular IT management courses, platforms for technology mobilization and management. The framework is also commonly used for IT management. The diagram depicts the variables involved in ITL framework layout. The ITIL framework is reported to fill existing needs for ITIL evaluations and projects. The report also suggests that the framework can be modified for use in dynamic projects, on a wider scale [15].

4) COBIT Framework: This was developed in 1996 by ISACA and the IT Governance Institute. The CobiT framework is set of best practices for IT management solutions and services. The latest of these frameworks is COBIT 5, which was founded in 2012 after 4 other frameworks evolved.

This would allow for a holistic governance and management of the information and related technology in an enterprise.

COBIT 5 "principles and enablers are generic and useful for enterprises of all sizes, whether commercial, not-for-profit or in the public sector" [12]. Therefore, an ordinary user, without much skill in technology can benefit from using the model for adoption processes of any technology.

\section{METHODOLOGY}

The research is intended to study issues that hinder and those allowing for cloud adoption in Botswana. Hence, this research will involve both qualitative and quantitative methods for analyzing these factors. With the findings, the study will help identify and influence the need for a local cloud computing framework for SME's in Botswana. A questionnaire tool was used to collect data from a number of selected companies around Gaborone and its surroundings.

\section{Qualitative and Quantitative research are defined as:}

1) Quantitative approach - uses numerical values to either infer, experiment or simulate[14]. In the case of this research, data collected will be used to infer findings from the population common characteristics and relationships from the sample data collected.

2) Qualitative approach - consider opinions, descriptions or feelings, rather than numerical data [19]. The data collected from the survey will bring out opinions of participants on factors in cloud computing adoption, and these will be used along research data to validate issues around cloud computing.

About 51 companies were contacted for sampling. These companies were selected from various industries, as follows: About 41 of these companies are registered as Information Technology (IT) companies in Botswana. These include IT sales, maintenance, support services, managed services, software developers, and infrastructure support services; 5 companies are academic institutions; 1 Private Telecommunications Organizations (PTO's); 1 Postal service company; and 3 Internet Service Providers SP's.

A convenience sampling method is a sampling method which depends on collecting data from a population available to participate in the research [19]. The researcher has to conveniently make available the questionnaire for the 
participants, and collect the questionnaires after a given and agreed time with the participants. Due to time factors and costs on the other methods of sampling, Convenience Sampling was favorable considering the limits to the research.

\section{FINDINGS}

This is based on the key findings from the collected data. These findings are matched with the research objectives. At the end, these results are intended to guide on whether a framework is required nor not, and if there is need to developing one for the local SMEs. These major findings are:

\section{A. Section 1: Demographics}

The section's intention is to establish that the company has an IT department and the number of employees per company. The findings show that:

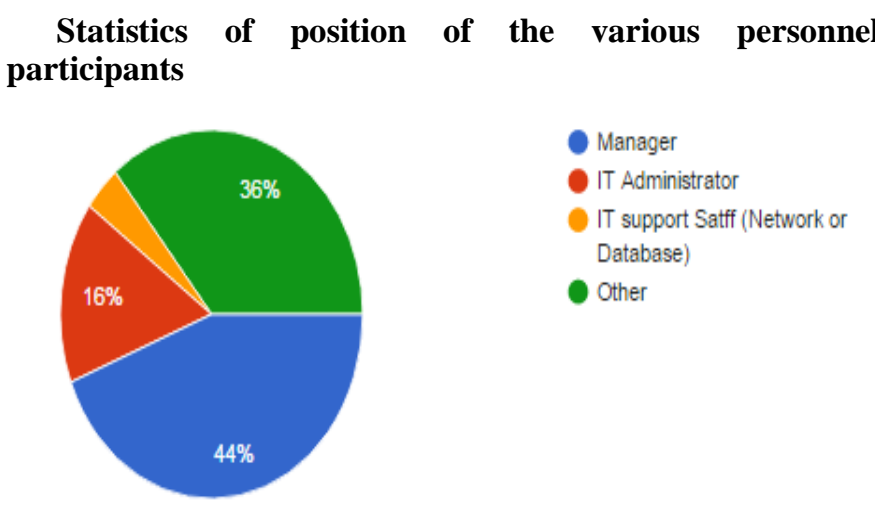

Fig. 1. Participants' position in the company.

1) Participant Position: The questionnaire was targeted for people or staff in companies who had knowledge or were part of the IT department. The results show that, most of the participants were company managers. Then other greater percentage was "others" option, and these mostly included technicians in the company, and in one case, a finance and accounting manager, who was involved with the IT department operations. Fig. 1 gives the statistics of position of the various personnel participants.

2) Company Employment Number: Considering the research is focusing on SMEs' in Botswana, one of the questions was intended to identify the differences between participating companies by the number of employees they have. The chart shows that only $28 \%$ of companies had employment of more than 250 employees. The remaining statistics indicate that the rest are SME companies, as they are employing 250 or less employees. What is significant yet, is that more than half of the indicated SMEs in this chart, are those employing at least 50 or less people (48\%), are indicated as small or micro companies as reported by Fjose. Fig. 2 gives the organizational population for participants employers.

\section{Organizational Population for participants' employers}

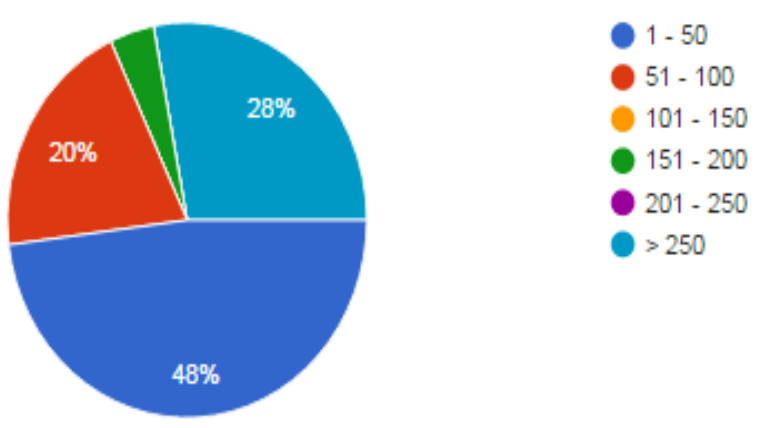

Fig. 2. Number of employees in the company.

\section{B. Section 2: Cloud adopters}

The section is intended to identify if the company uses cloud services in their business operations. One of the questions in this section was used to give examples of cloud services to assist the participant to understand what cloud services are commonly used by consumers on a general use basis. The examples used were common to Botswana context for most users (for example: Facebook, Google apps, MS Azure and Google drive).

1) Companies using Cloud Computing: There is no uncertainty on the participant whether they are using cloud or not. The results show that $60 \%$ of companies are using cloud services, whilst $40 \%$ said "no" to the use of cloud computing services. Fig. 3 shows the companies using cloud services in Botswana.

\section{Companies using Cloud services in Botswana}

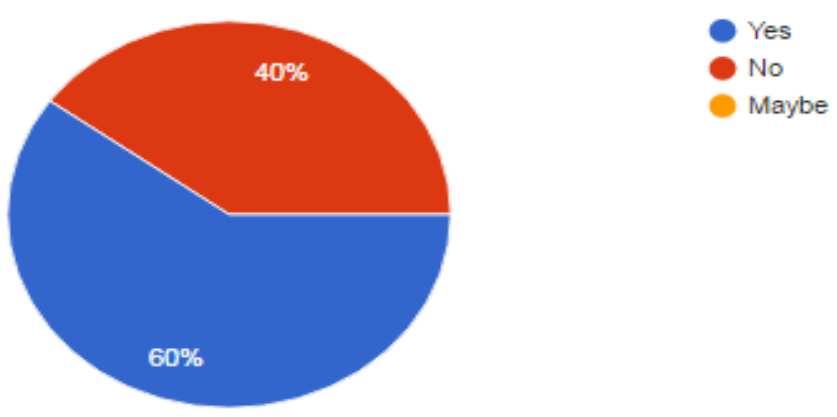

Fig. 3. Number of companies using Cloud Computing Services.

2) Cloud Computing Services models used: Cloud computing service models are categorized into SaaS, IaaS and PaaS. Participants needed to identify which models they were using for their organizations. The results show that they $66.7 \%$ of these companies that are cloud adopters are 
using IaaS (66.7\%), more than SaaS (53.3\%) and PaaS (13.3\%). The analysis of this results show that some of the companies are using more than one service model for their operations. Fig. 4 gives the service models used by cloud adopter companies.

IaaS, PaaS, SaaS services for participating Companies

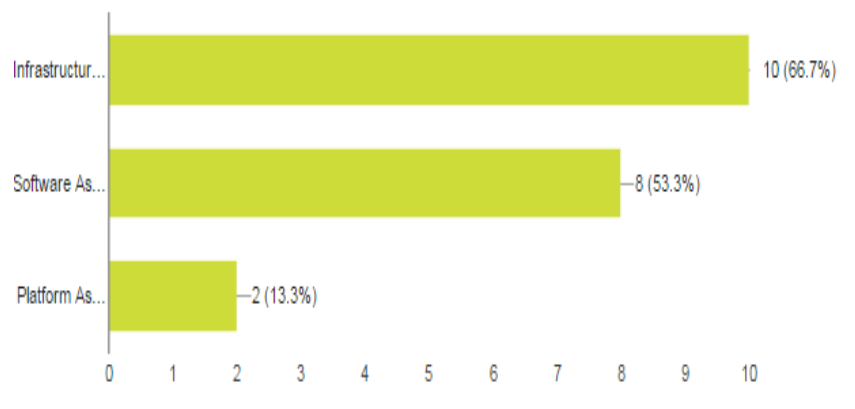

Fig. 4. Service models used by cloud adopter companies.

3) Examples of cloud services: examples used were included in the questionnaire to assist the participants have an idea of what common services the cloud has, which are beknown to Botswana cloud users. The results showed that companies could relate to cloud usage, and even the most unique software Microsoft Azure by Microsoft products, had an $8.7 \%$ acceptance of use. Facebook was only at $60.9 \%$, whilst google apps and DropBox were both at $69.6 \%$, being the highest in use. Only about $26.1 \%$ indicated to be using other cloud services. Fig. 5 shows the examples of clod services that are used by companies.

\section{Examples of Cloud services that companies are using}

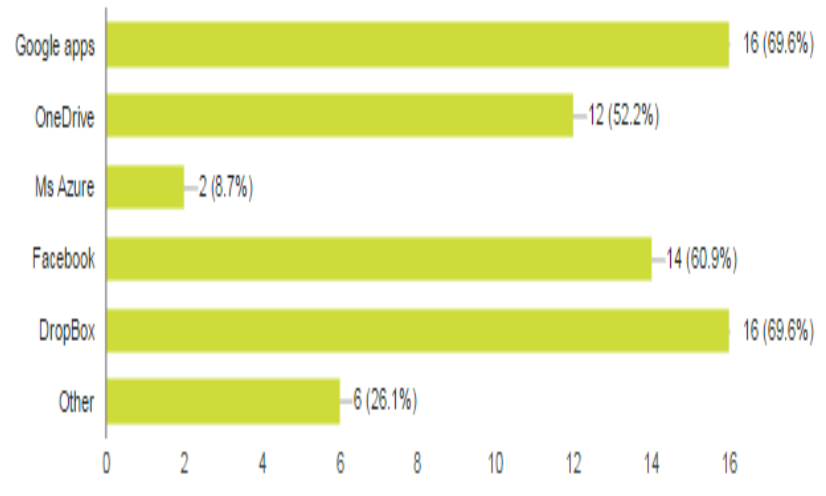

Fig. 5. Examples of cloud services common for local use.

\section{Section 3: Cloud Providers}

This section considers cloud services the participating companies provide to their clients, and to identify the extent of these companies' provisions, and what services they are providing to the clients. The results show that:
1) Participant Providing Client with Cloud Business/Service: At least $28 \%$ of companies mentioned providing cloud services to their client, whilst $12 \%$ were unsure if there were doing so. Most of the companies, of $60 \%$, reported not to be providing these services for their clients or service consumers. Fig. 6 shows the companies providing cloud services to other companies.

\section{Companies providing cloud services to other companies}

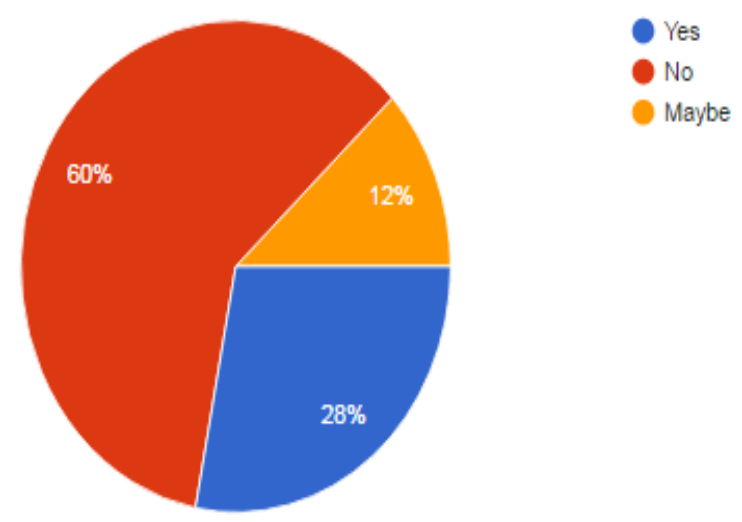

Fig. 6. Participant providing cloud services to their clients.

Cloud services provided by other companies in Botswana

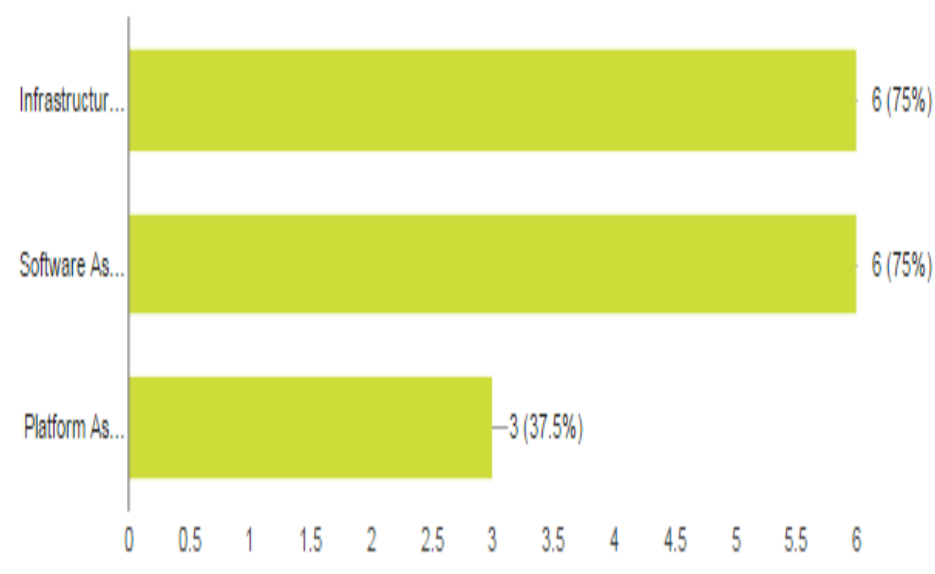

Fig. 7. Service models used by participants' clients.

2) Service Models Provided by Participants to Clients:

The fact that some companies are providing cloud services to their clients as business, it is interesting to learn results that most of the service models provided are IaaS and SaaS, which are both rated at $75 \%$ from the graph below. PaaS does not seem to be common for business at first hand or third party, as it is reported only at $37.5 \%$ for client usage or consumer service. Fig. 7 shows the cloud services provided by other companies in Botswana. 
3) Number of Companies Receiving Service from Local Companies: The results show that $85.7 \%$ of companies receiving business for cloud services from a local company, they are at least 10 or less. In comparison, only $14.3 \%$ of companies are reported to provide cloud services to more than 40 companies. There is no information on the range between 10 and 40. Fig. 8 shows the number of client companies for cloud services by the participants company.

\section{SME's Cloud Providers in Botswana}

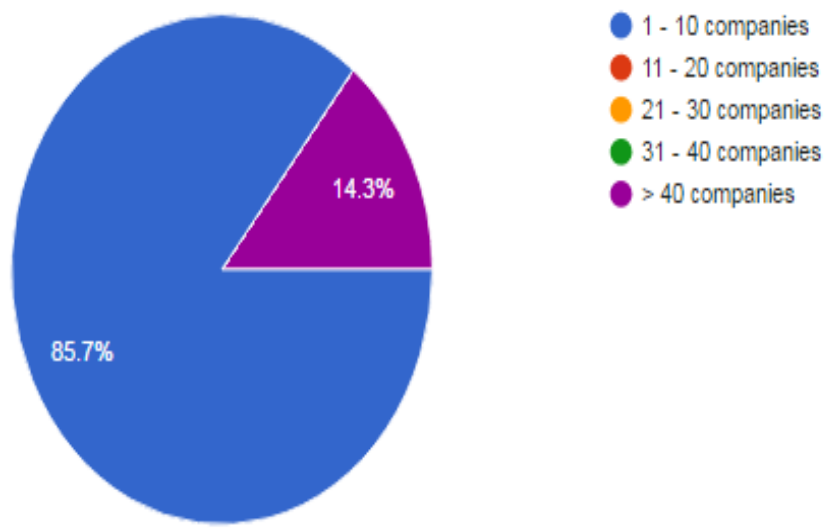

Fig. 8. Number of client companies for cloud services by the participants' company.

\section{Section 4: Cloud Challenges}

This section shows results on challenges that participants have reported to face in their organizations.

1) Location Access Challenges: Most of the participants showed they struggle to access cloud services from their home networks (56\%), than on their mobile devices (48\%), and least at work (20\%). Fig. 9 gives the challenges accessing cloud at home, work or in mobile device.

Challenges of using the cloud: Home or work?

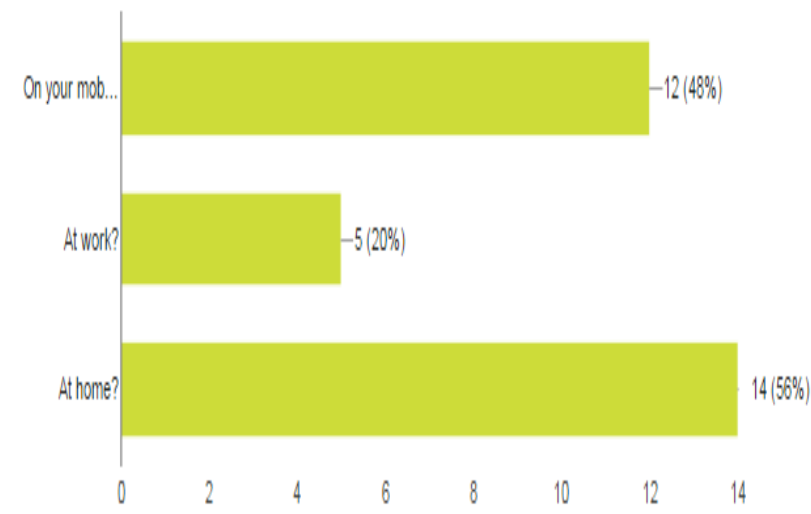

Fig. 9. Any Challenges accessing Cloud at home, work or in your mobile devices.
2) Access For Work or Personal: It needs to be established if the services being accessed were for personal or work activities from the locations noted above in Section 4(1). It shows that most of these failing accesses were for personal use at $81.8 \%$, than for work purposes at $31.8 \%$. Fig. 10 shows the results for access at home or work for personal or work purposes.

\section{Use of cloud services for participants}

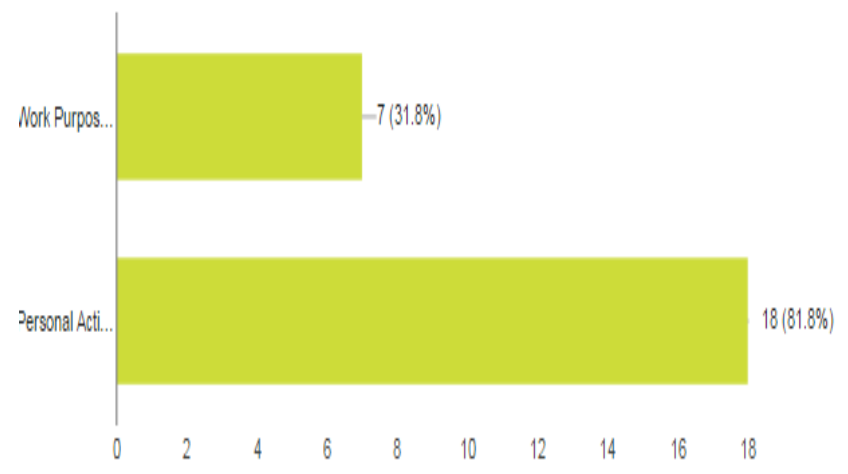

Fig. 10. Results for access at home or work for personal or work purposes.

3) Local Challenges with Cloud Services: Since the literature review indicated that a number of surveys have indicated that there are issues in cloud computing, the results from the survey indicate the same. The table below shows the results from the survey. Fig. 11 shows the challenges of cloud services for companies.

Challenges of cloud services for companies

\section{Do these issues affect your company negatively?}

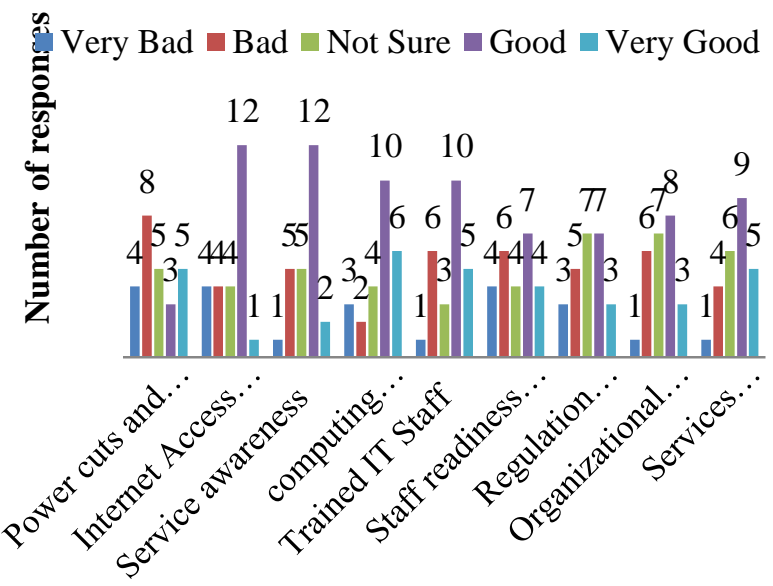

Fig. 11. Issues affecting Cloud services in local companies. 
4) Participants Opinions on their cloud use challenges: Some of the results in this section indicate participants opinions on challenges they face in their companies. These include points such as:

"My company is not aware of these services, they don't want to use them"

"Abuse by clients and/or employee"

"We also sell cloud services to our clients"

"Resistance to change I guess"

"Unreliability of ISP"

"Security"

"The need for skilled personnel both in-house and customer. BYOD deviced serve as a vulnerabililty, so there is need for security awareness regardless of security measures put in place"

"Security issues e.g. DDOS Attacks as well as Faulty Interoperability of Cloud service APIs"

These indicate the concerns of the participants they face in the business as they use cloud services. These are mostly not included in the previous parts of the section.

\section{E. Section 5: Cloud Successes}

This section considers participants results on benefits of cloud services to their organization, and to some point personal benefit. The section includes the participant opinions on their successes and benefits from the services.

1) A question in this section considered thoughts and opinions of the participants on what impact and benefits the cloud has provided for them, and some of these responses were:

"e sava memory" translated as "It saves memory"

"There is greater market, ease of acquisition of services offered by my company"

"efficiencies, accessibility and lowering costs"

"Reliable backup of important information like student exam codes for modules like java programming"

"boosted productivity and service delivery"

"storage and scalability"

"our company specializes in multimedia production, which requires us to share big video and audio data files with clients across the globe. In the past we had to spend a lot of money sending these files through couriers like DHL. This has saved us time and money"

2) The statistical results of these improvements are shown below in the diagram. It shows that these benefits were across different levels of the participants daily activities, be it personally (83.3\%), at work (58.3), and for the delivery of the company objectives (75\%) and has seen other staff members benefiting from its use (45.8\%). Fig. 12 gives the benefits to client for using services.

\section{Cloud services resourcefulness for participants}

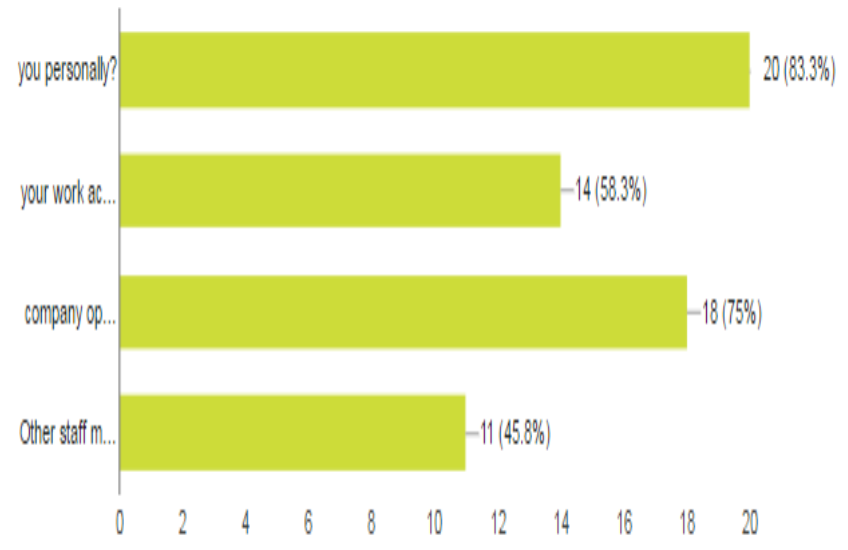

Fig. 12. Benefits to client for using cloud services.

3) Using other positive responses from other surveys, gave a list of issues that the participants may also be identifying as benefits for their organizations. The results are shown in the diagram below. The results show that many of these benefits, the participants have also benefited from them as we see rates of "good" and "very good" showing a greater number of responses in the diagram. Fig. 13 shows the positive impacts to cloud computing users.

\section{Cloud access challenges impact in Companies}

\section{Do these issues affect your company positively?}

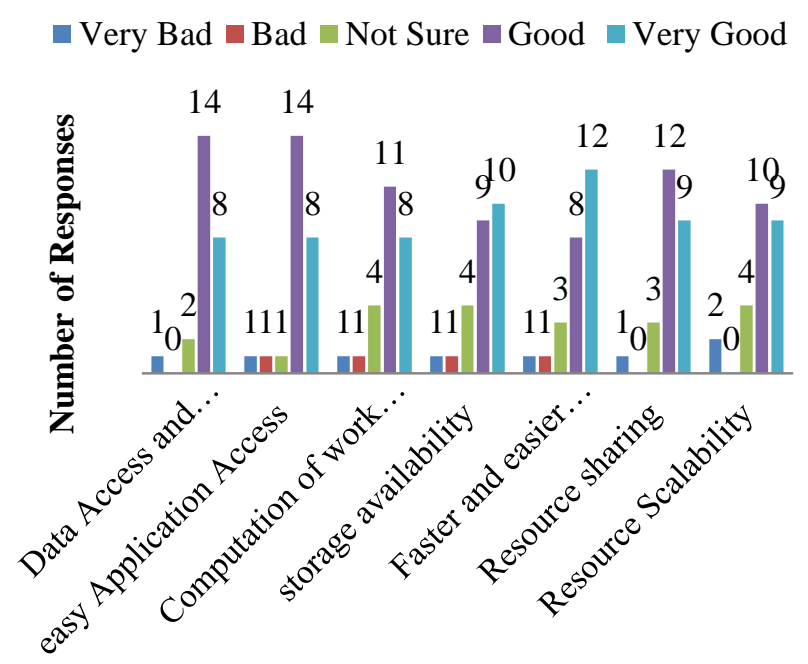

Fig. 13. Positive impacts to cloud computing users. 
4) The final part of the section was to enquire from the participants if they have any successes to share on how cloud services benefited their organizations. Their responses were:

"Re baya sengwe le sengwe mo lerung" Translated as "we keep everything on the cloud"

"The use of our private cloud has increased ICT awarencess and use in the organization.. This has also brought in product innovation and better efficieny. "

"We have implemented more than 7 clients on cloud in the last 4 months"

"we have been able to store our previous work on the cloud making it easy for us to share these with prospective clients and organizational use only at a touch of a button."

"Advertising”

"Reliable backing up and retrieval of important information anywhere within the institution”.

\section{SUMMARY OF FINDINGS ON OBJECTIVES}

\section{A. Objective 1: SMEs and Cloud Computing Services} Effectiveness

1) Cloud Use

- There are a lot of SME's, more than larger organizations that are using cloud services. The results showed that $60 \%$ of companies are using cloud services, and it also showed that at least $72 \%$ of these companies are SMEs. This indicates likelihood that since the majority of companies are SMEs, some of them are included in providing cloud services or business for their clients.

- What is more interesting is that, the majority of the companies providing cloud services to other companies, shows to be providing to a maximum of 10 companies per survey responses by participant. This could either be because it is a small company which is providing these services, and is still establishing itself to reach out for more business; or that there are challenges in cloud adoption by companies. The results does not show much challenges in Botswana adopting to cloud services,

2) Access

- Access of cloud services did not seem a problem at work for the participants. They only showed a $20 \%$ challenge at work, but more challenges for their home access.

- The challenge in access of cloud services was mainly on personal usage or activities, hence showing a reduced percentage $(31.6 \%)$ for challenges on work activities, than personal activities which are at $81.8 \%$.

\section{B. Objective 2: Challenges and Successes for SMEs}

\section{1) Challenges}

Some of the challenges seen from other surveys were used for the survey, and the scores showed positive results from the respondents. Most challenges, the participants indicated that they did not have them as challenges for their organizations. These include Internet access and availability, services awareness, computing resources availability, trained staff, staff readiness and awareness, organizational trust and services availability and access.

Though some of these challenges didn't show as challenges, most participants were not sure if these were challenges or not. For instance, "organizational trust" and, "standards, regulation and policy" showed about $30 \%$ uncertainty, whilst others (32\%) felt it was bad and others (40\%) felt it was good. These results are not showing sufficient disparities to understand if these are challenges or are good variables for cloud adoption. The biggest rated challenges were power outages and power cuts. Concerns mentioned and were common between participants were:

- Unreliability of Internet Service Provision

- Security issues

- Lack of skilled personnel

- Awareness issues

- Integration issues and interoperability

2) Benefits

The feedback from participants was very positive as all the variables in the tables indicated for a positive impact in an organization, and were rated above $76 \%$. Very few respondents indicated that they were unsure on a range of $4-16 \%$, whilst a maximum of $8 \%$ showed having these variables indicating challenges in their organizations.

Many respondents are happy with the cloud as it brought out benefits such as:

- Backup of data in the cloud, and reliable

- ICT awareness

- Increased productivity and efficient service delivery

- Low costs

- Online readily available storage

- Easy acquisition of services

\section{Objective 3: Frameworks used for Technology Adoption}

Participants indicated slim disparities on whether policy, regulation and standards could be a problem for their organizational business. Since there is no policy in Botswana or regulation for cloud computing, a question on whether regulation or policies are considered on cloud adoption was never included in the questionnaire.

\section{IMPLICATION RESEARCH}

Finally, conclusions on the results collected from participants are revealing positive cloud adoption in Botswana. Though, the adoption rate is very low considering that issues of awareness are impending cloud adoption decisions. Objectives for research are being answered as follows from the survey: 


\section{A. Objective 1: SMEs and Cloud Computing Services} Effectiveness

A number of companies, especially SME's show that they are using cloud services in Botswana. A report about SubSaharan Africa countries agrees with the fact that cloud computing is slowly taking root in these countries and that SMEs are also stakeholders in this growth[2]. The report showed that SMEs make the most of the firms per country, and the results indicated too that a lot of companies reflected being either micro, small or medium businesses, and only very few were large enterprises.

\section{B. Objective 2: Challenges and Successes for SMEs}

The statistics are showing a very positive uptake of cloud adoption, as the results under challenges companies may be facing for cloud usage, show that the indicators used, many seemed happy with them. Hence, the challenges were very few, that were indicated to be a challenge for cloud uptake. These were power outages and cuts, and staff readiness and awareness, standards and policy, and organizational trust. Albeit these challenges, showing a marginal difference between the bad and good side of these indicators, other indicators were showing high positive scaling. The indicators showing greater rates as challenges are confirmed by the Nigerian research for universities, for example, $80 \%$ of universities showed that a lack of regulation on cloud adoption is a security concern [3]. Though the survey results showed a low matrix result on challenges companies may face, in the participants views, many showed concerns on security issues.

The results showed that cloud adopters were happy with the indicators used. Most importantly, some indicated successes on usage of using cloud services. One company revealed registering about 7 clients, for cloud business in a period of 4 months. Some companies recorded "increased productivity and efficiency" in their services.

\section{Objective 3: Frameworks used for Technology Adoption}

Various frameworks were discussed in the literature review. These are TMR, TOE, ITIL and COBIT frameworks. Botswana only has the Maitlamo (2004) ICT policy for all ICT aspects in Botswana. The Botswana ICT Master Plan in 2012 was intended to assist the Botswana government to come up with ways to compliment the initiative on Maitlamo policy, where all resources in ICT are to be harnessed to improve ICT adoption in the country.

\section{Objective 4: Need to Develop a Cloud Computing \\ Framework for SMEs in Botswana}

Considering that cloud adoption does not seem to be having so many challenges in Botswana, there is no need for a framework to be developed yet. Further research is needed on cloud adoption in Botswana to see if a framework is absolutely necessary. With the research survey done, it still shows that there is further survey needed to find out the frameworks companies use or some may need, and also consideration on the understanding of how a framework works, despite have regulatory policies and standards.

\section{RECOMMENDATIONS FROM THE STUDY}

The recommendations are made with relation key findings of this research. A number of issues and questions were also raised to be included in this research, but a need for further research on this topic is needed. These recommendations include:

1) As Botswana has a good number of SMES adopting cloud computing, there is not clear understanding of how many of these companies are technology driven and using such services. There is no record either of the SMEs who are using cloud computing, which could be recommended as future work or research. This would help the statistics department of Botswana, BOCRA, ICT companies listing to know needs to be addressed.

2) A lack of awareness was indicated as a challenge. An establishment of what kind of awareness is needed can be undertaken as a research to survey the need for information dissemination or training to empower SME's on benefits of cloud computing.

3) Given enough time and resources for the research would have given more grounded results, and probably reached other areas around the country. Therefore, further research on the topic could reach out to the rest of the country's SME's.

4) Frameworks present various models on implementing technologies. Another research, could target these various technology frameworks, and with the assistance of this research, map aspects or principles that could be suitable for developing countries, on cloud adoption or technology adoption.

\section{CONCLUSION}

The research indicates that indeed Botswana SME's are adopting cloud computing services. An ICT policy for Botswana is the only tool that guides ICT adoption and related issues in Botswana. The most challenging to conclude is the recommendation or suggestion of a framework to use by local SMEs in Botswana. The results show very positive adoption by cloud adopters, and showing they are not facing many challenges on cloud services usage. One of the main issues recurrent in a number of participants was lack awareness by users and companies. This could answer for the $40 \%$ of results showing non-adopters, that it could be a lack of awareness or disinterest to the services.

\section{REFERENCES}

[1] A.D Abubakar, J. M. B. I. A., “. Cloud COmputing: Adoption Issues for Sub-Saharan African SMEs”, EJISDC, 62(1), pp. 1-17.2014

[2] Abubakar, A., Bass, J. M. \& Allison, I., “ Cloud Computing: Adoption For Sub-Saharan African SMEs". Electronic Journal of Information System in Developing Countries, 62(1), pp. 1-17,2014.

[3] Akin, O. C., Matthew, F. T. \& Comfort, D. Y., "The Impact and Challenges of Cloud Computing Adoption on Public Universities in South western Nigeria”. IJACSA, 5(8), pp. 13-19.,2014.

[4] Alshamaila, Y. \& Papagiannidis, S., "Cloud Computing adoption by SMEs in the north east of England: A multi-perspective framework". Emerald Insight, 26(3), pp. 250-275,2012. 
[5] BOCRA, "Survey on Internet Connectivity in Key Strategic Areas in BOtswana (Hospitality fFacilities)", Gaborone: BOCRA,2014.

[6] Botswana, U. o., 2009. www.ubotho.net/MDP/it-support. [Online] Available at: www.ubotho.net [Accessed 1011 2016].

[7] Carroll, M. \& Ramsingh, K., "Cloud Computing 2012 Survey Results", Johannesburg: Deloitte,2012.

[8] Connolly, E., Norman, D. \& West, T., "Small Business: An Economic Overview in Small Business Finance Roundtable", Sidney: Reserve Bank of Australia,2012.

[9] Doherty, E., Carcary, M. \& Conway, G., "Migration to the Cloud: Examining the drivers and barriers to adoption of cloud computing by SMEs in Ireland: an exploratory study. Emerald Insight”, 22(3), pp. 512 $-527,2012$.

[10] Eastman, R., 2010. SMB Research - Sizing up Small-to-Medium Business (SMB). [Online] [Accessed 0112 2016].

[11] Fakieh, B., Blount, D. Y. \& Busch, D. P., "Success in the Digital Economy: Cloud Computing", SMEs and the Impact to National Productivitiy. Auckland, New Zealand, 25th Australasian Conference on Information Systems, 2014.
[12] Garsoux, M., "COBIT 5 ISACA's new framework for IT Governance", Risk, Security and Auditing, s.l.: ISACA,2012.

[13] .IST-Africa, 2015. www.ist-africa.org/home/default.asp. [Online] Available at: www.ist-africa.org,[Accessed 1011 2016].

[14] Kothari, C., "Research Methodology: Methods and Techniques". 2nd ed. New Delhi: New Age Internationa (PTY) LTD,2014.

[15] .McNaughton, B., Ray, P. \& Lewis, L., "Designing an evaluation frameowkr for IT service management",. ELSEVIER, 47(003), pp. 219225,2010.

[16] Sebina, P. M. 1. M., Moahi, K. H. \& Bwalya, K. J., "Digital Access and E-Government: Perspectives from Developing ad Emerging Countries". Hershey, United States: Information Science Reference,2014.

[17] .Simba, J. K., "Adoption of Cloud COmputing amoung Small to Medium Enterprises in Kenya". Erepository,2014.

[18] Tsimane, E., "Botswana Looks to Cloud Computing", Gaborone: Sunday Standard,2013.

[19] Walliman, N., "Research Methods: The Bacis". 1 ed. London and New York: Routledge: Taylor and Francis Group,2012.

[20] Yevgeniy, S., "IBM Launches Cloud Data Center in South Africa", Johannesburg: IBM,2016. 